\title{
NOVOS ATORES INTERMEDIÁRIOS NA REGULAÇÃO DA EDUCAÇÃO EM PORTUGAL
}

\author{
Luís Miguel Carvalho (Inst. de Educação/Universidade de Lisboa)* \\ Sofia Viseu (Inst. de Educação/Universidade de Lisboa)** \\ Catarina Gonçalves (Inst. de Educação/Universidade de Lisboa)***
}

\begin{abstract}
RESUMO
Este artigo apresenta uma pesquisa sobre dois atores que entraram recentemente na cena educativa portuguesa, pela via da filantropia e com o objetivo de apoiar, produzir e difundir conhecimento para melhorar as políticas públicas e informar as decisões dos cidadãos. Procurando analisar os produtos que materializam e operacionalizam a intervenção dos dois atores coletivos, o artigo tem por objetivo contribuir para a discussão sobre a emergência, a expansão e o papel deste tipo de atores no quadro dos processos de reconfiguração dos modos de regulação dos sistemas educativos e da intensificação da mobilização do conhecimento em política. A pesquisa baseou-se numa extensa análise documental e em entrevistas, evidenciando o modo como esses atores, que se apresentam como mediadores e peritos, atuam no espaço público, bem como as regras que conformam suas proposições sobre os sistemas educativos e acerca das melhores formas de governá-los.

Palavras-chave: Atores intermediários. Regulação da educação. Conhecimento para a política.
\end{abstract}

\section{ABSTRACT \\ NEW INTERMEDIATE ACTORS IN THE GOVERNANCE OF EDUCATION IN PORTUGAL}

This article presents a research on two actors who recently entered the Portuguese educational scene through philanthropy and with the purpose of supporting, producing and disseminating knowledge to improve public policies and inform citizens' choices. By analysing the products that materialize and operationalize their intervention, we aim to contribute to the discussion about the emergence, expansion and role of this type of actors within the reconfiguration of the governing of education systems and in the frame of an increasing mobilization of knowledge for policy. The study is based on an extensive document analysis and on interviews. It shows how these actors, who act as mediators and experts, act in the public space, as well as the rules that shape their propositions on educational systems and how these should be governed.

Agregado em Educação pelo Instituto de Educação da Universidade de Lisboa. Professor catedrático do Instituto de Educação da Universidade de Lisboa. E-mail: lmcarvalho@ie.ulisboa.pt

** Doutora em Educação, na especialidade de Administração e Política Educacional, pelo Instituto de Educação da Universidade de Lisboa. Professora Auxiliar do Instituto de Educação da Universidade de Lisboa. E-mail: sviseu@ie.ulisboa.pt

*** Mestre em Educação, na especialidade de Administração Educacional, pelo Instituto de Educação da Universidade de Lisboa. Doutoranda em Educação pela Fundação para a Ciência e Tecnologia do no Instituto de Educação da Universidade de Lisboa. E-mail: catarinagoncalves@ie.ulisboa.pt 
Keywords: Intermediary actors. Education governance. Knowledge for policy.

\section{RESUMEN}

\section{NUEVOS ACTORES INTERMEDIOS DE LA GOBERNANZA DE LA EDUCACIÓN EN PORTUGAL}

Este artículo presenta una investigación sobre dos actores que ingresaron recientemente en la escena educativa portuguesa a través de la filantropía y con el propósito de apoyar, producir y difundir el conocimiento para mejorar las políticas públicas e informar las decisiones de los ciudadanos. Al analizar los productos que materializan y operan su intervención, nuestro objetivo es contribuir a la discusión sobre el surgimiento, la expansión y el papel de este tipo de actores en el marco de la reconfiguración del gobierno de los sistemas educativos y de la creciente movilización del conocimiento en política. El estudio se basa en un extenso análisis documental y en entrevistas, que han puesto en evidencia como estos actores, que se presentan como mediadores y expertos, actúan en el espacio público, así como las reglas que dan forma a sus proposiciones sobre los sistemas educativos y cómo deben ser gobernados.

Palabras clave: Actores intermediarios. Gobernanza de la educación. Conocimiento para la política.

\section{Introdução}

Nos últimos anos temos assistido em Portugal ao crescimento e expansão de novos atores nas políticas educativas, em particular de organizações privadas e filantrópicas. Entre outras funções que a si mesmas atribuem, essas organizações afirmam-se comprometidas em apoiar, produzir e difundir conhecimento para melhorar as políticas públicas e informar as decisões privadas. Este fenômeno segue uma tradição há muito existente, por exemplo, nos Estados Unidos e na América Latina, e tem ganhado maior expressão na Europa (BERNARDI et al, 2018; FELDFEBER, 2018; MARTINS, 2016; MCGANN, 2018).

Em Portugal, esses atores têm entrado em cena na esfera comunicacional das políticas públicas com o propósito, entre outros, de produzir conhecimento sobre educação e melhor esclarecer a sociedade portuguesa. Encontram-se nesse conjunto o aQeduto e o EDULOG, ambos tornados públicos em 2015, sobre os quais incide a pesquisa que apresentamos neste artigo. O interesse pelo estudo deste tipo de atores advém da perceção, testada pela investigação, segundo a qual têm assumido um papel relevante na regulação da educação, desempenhando uma acrescida importância nos processos de decisão política e configurando até a emergência de novos espaços transnacionais e intranacionais de política (BALL, 2016; LAWN; LINGARD, 2002). Por isso, o nosso propósito é contribuir para uma discussão sobre a emergência, a expansão e o papel desses atores no quadro dos processos de reconfiguração dos modos de regulação dos sistemas educativos (MAROY, 2012) e da intensificação da mobilização do conhecimento nos contextos políticos (LEVIN; COOPER, 2012). Mais precisamente, temos o objetivo de encontrar os modos através dos quais esses atores se tornam atuantes nos processos de regulação (CARVALHO, 2006), isto é, de melhor conhecer e analisar os produtos que materializam e operacionalizam a sua ação.

$\mathrm{O}$ artigo está organizado em três seções. $\mathrm{Na}$ primeira seção apresentaremos o modo como foi construída a arquitetura do nosso estudo, no que diz respeito à construção do olhar teórico que nos guiou, aos princípios que orientaram o estudo empírico e aos critérios que presidiram a escolha do aQeduto e do EDULOG na nossa pesquisa. Nas seções seguintes daremos conta das principais características desses dois atores que ilustram o seu 
papel de atores intermediários, nas suas dimensões cognitivas (incidindo sobre o modo como se apresentam e os pressupostos básicos relativos ao papel social que desempenham e o sentido que atribuem aos sistemas educativos) e dimensões sociais (compreendendo as atividades de geração, publicação, convocação e outras que desenvolvem para atingir os seus propósitos). $\mathrm{O}$ artigo termina com algumas considerações finais, nas quais traçamos algumas linhas interpretativas sobre o seu papel como atores intermediários e suas relações com a alteração dos contextos significativos e dos modos de produção das regras que visam orientar e controlar a ação no setor educativo.

\section{Problemática e metodologia}

A emergência e afirmação de novos atores nas políticas educativas, que se apresentam com o objetivo de produzir e difundir conhecimento sobre educação e melhor esclarecer quer decisores políticos quer leigos, pode justificar-se graças a dois fenômenos que, estando intimamente ligados, marcam as políticas educativas das últimas décadas em Portugal, à semelhança do que sucede noutros países europeus e da América Latina.

Desde logo, temos assistido à erosão (e quebra) de um modo de regulação "burocrático-profissional", uma resultante histórica da concertação entre a regulação estatal, de tipo burocrático e administrativo, e a regulação profissional, isto é, uma regulação baseada no saber dos professores (BARROSO, 2013). Esta aliança manifestou-se na negociação, entre Estado e sindicatos, de instrumentos a priori, sustentados na regra e na autoridade formal, na qual se incluíam, por exemplo, os quadros jurídico-normativos e a definição de tabelas salariais. Em sua substituição, tem-se promovido uma regulação centrada na negociação de instrumentos informativos e persuasivos, privilegiando modos de coordenação da ação coletiva a posteriori, como são exemplos os contratos, as boas práticas, a avaliação e a prestação de contas, os rankings e as comparações internacionais (OZGA, 2008, 2009).

Ocorre que esses novos instrumentos apelam crescentemente ao conhecimento - e à produção de conhecimento-, a dados e evidências que, deste modo, têm ganho considerável importância nos processos de decisão: a recolha, a circulação e a comparação são cada vez mais usadas como recurso para a construção das políticas (VAN ZANTEN, 2013). Ora, é neste espaço, perante a necessidade de produzir, organizar e difundir conhecimento, que esses novos atores encontram e afirmam crescentemente o seu lugar na ação pública.

Olhando para o contexto português, destacamos dois atores que convergem nessa vocação: o aQeduto e o EDULOG. Sobre estes recai o nosso estudo.

$\mathrm{O}$ aQeduto: avaliação, qualidade e equidade em educação entrou na cena pública em 2015 por meio de uma regular e assinalável presença na mídia, apresentando-se com o objetivo de fornecer informação útil e credível para explicar os resultados dos estudantes portugueses no PISA a decisores políticos e leigos. Estas intenções sinalizam um fenômeno novo em Portugal, em que o trabalho de transformar intencionalmente os resultados do PISA em conhecimento para a política tem sido ocasional e aleatório (CARVALHO; COSTA; GONÇALVES, 2017). O aQeduto surgiu como ideia de um anterior presidente do Conselho Nacional de Educação ${ }^{1}$ (CNE) - David Justino (20132107) - e tornou-se uma iniciativa conjunta entre o CNE e a Fundação Francisco Manuel dos Santos (FFMS), uma importante organização filantrópica nacional. A FFMS foi criada em 2009 por Alexandre Soares dos Santos, um dos maiores empresários do país, que foi, até 2013, o CEO de um grande grupo econômico que opera em escala nacional e internacional nas áreas do comércio e distribuição alimentar. A FFMS publica e financia investigação, promove discussões sobre tópicos sociais, trabalha com "especialistas" nas suas atividades e produz dados sobre Portugal e a Europa usando o "meio digital", com a missão de "facultar o acesso à informação a todos os cidadãos" (FUNDAÇÃO FRANCISCO MANUEL DOS SANTOS, 2017). É no website da FFMS que estão hoje alojados os materiais produzidos no âmbito do aQeduto.

1 O CNE é um órgão consultivo de política educacional do Ministério da Educação. No período 2013-2017, o CNE passou a defender uma abordagem mais centrada na produção de conhecimento baseado em evidência, ao contrário da sua anterior vocação para a produção de conhecimento para a política com uma abordagem mais ampla e menos focada em números. Ver Conselho Nacional de Educação (2015). 
No mesmo ano, o EDULOG entrou na cena educativa como o primeiro autointitulado think tank exclusivamente dedicado à educação em Portugal. $\mathrm{O}$ EDULOG afirma como seu objetivo disponibilizar informação objetiva e relevante para os decisores políticos numa tentativa de "influenciar as políticas educativas no sentido de resolver os problemas mais prementes do sistema educativo" (CORREIA, 2017). Esta agenda educativa, tornada explícita e pública, sinaliza, igualmente, um fenômeno recente em Portugal (VISEU; CARVALHO, 2018). O EDULOG nasceu no âmbito das atividades filantrópicas de Belmiro de Azevedo (1938-2017), também ele um dos maiores empresários portugueses que, entre 1974 e 2015, construiu e dirigiu a SONAE, uma holding internacional, sediada em Portugal nos setores da distribuição, comércio, construção, turismo e imobiliário, tecnologias, telecomunicações e comunicação social. Em 2015, Belmiro de Azevedo anunciou a sua reforma para se dedicar a atividades de responsabilidade social, entre as quais a criação do EDULOG, considerado por ele um legado que queria deixar ao país (EDULOG, 2017).

$\mathrm{O}$ estudo incide sobre esses dois atores por entendermos que trazem certa novidade na cena educativa portuguesa. Por três razões: pela afirmação inequívoca da sua missão em produzir ou apoiar a produção de conhecimento especializado para a política, de modo a orientar e dar sentido às políticas educativas e ao envolvimento dos atores nesses processos; por se tratarem de organizações de pequena escala, com uma estrutura simples, mínima, mas que são suportadas por fortes e explícitas conexões ao mundo empresarial, pois nasceram por iniciativa privada e no âmbito de atividades de filantropia de grandes empresários portugueses, o que sinaliza igualmente uma novidade no panorama nacional; pela procura ativa, e que explicitam repetidamente, em envolver "especialistas" e em mobilizar atores vindos de diferentes mundos, sejam da academia, das empresas ou da administração educativa.

Para melhor compreender o seu papel na cena educativa portuguesa, usamos a noção de atores intermediários (NAY; SMITH, 2002), isto é, atores que se envolvem num conjunto de operações cognitivas e sociais para a construção e estabilização de interações entre ideias, indivíduos e dispositivos técnicos. Para compreendermos o modo como pro- curam orientar e dar sentido às políticas educativas, recorremos a duas dimensões de análise: a) a cognitiva, na qual consideramos a sua representação de si (como se autoapresentam os atores) e as razões que justificam a sua intervenção (a afirmação da sua missão e o que imaginam para os sistemas educativos e formas como são governáveis); b) a social, na qual inquirimos as atividades que conduzem e os modos de intervenção que privilegiam.

Inspirados nos princípios metodológicos da network ethnography, a nossa pesquisa sobre esses atores começou por incidir sobre a sua extensa e massiva presença material online, entendida como um recurso para o estudo de novos atores e novas formas organizacionais especializadas na construção e uso das novas tecnologias com fins políticos explícitos (HOWARD, 2002). Conduzimos uma análise sobre uma considerável diversidade de conteúdos, incluindo os seus websites, páginas de redes sociais (como o Facebook e canais Youtube), artigos da mídia, informação de divulgação sobre as suas conferências e seminários e chamadas para apoio financeiro a atividades de investigação.

Numa segunda fase foram conduzidas entrevistas à coordenadora do $\mathrm{aQeduto}{ }^{2} \mathrm{e}$ à secretária geral do EDULOG $^{3}$ (citadas neste texto, respetivamente, como "Coordenadora do aQeduto" e "Secretária Geral do EDULOG”). Atendendo à extensão dos dados disponíveis online, estas entrevistas foram pensadas para preencher informação em falta e trazer novos contributos sobre as (auto)representações dos propósitos e atividades que conduzem. As entrevistas decorreram como conversas informais, em que as questões e os tópicos foram emergindo naturalmente (COHEN; MANION; MORRISON, 2007).

Os dados foram analisados a fim de melhor compreender de que modo o conhecimento especializado é produzido e disseminado e como essas duas organizações procuram orientar e dar sentido aos processos políticos da educação em Portugal.

\section{A dimensão cognitiva: (auto) apresentação e razões para agir}

Neste ponto apresentamos a dimensão cognitiva dos dois atores intermediários sobre os quais

2 Realizada em Lisboa, no dia 9 de fevereiro de 2017.

3 Realizada em Lisboa, no dia 21 de novembro de 2016. 
incidiu a pesquisa e que se concretiza por meio de um trabalho de mediação e a afirmação de determinados racionais para agir.

\section{Mediação}

Uma primeira característica comum que se destaca nesses dois atores consiste no modo como se apresentam, enquanto mediadores e peritos, atuando no espaço público fundamentalmente por meio de processos de mobilização, fabricação, disseminação e legitimação do conhecimento especializado. Esta mediação tanto é concretizada através do recurso a especialistas internos, no caso do aQeduto, como é construída externamente, conforme ocorre no EDULOG.

\section{aQeduto: a mediação através da expertise interna}

$\mathrm{O}$ aQeduto reivindica claramente o propósito de construir "informação credível e sustentada" sobre a variação dos resultados dos estudantes portugueses nos testes PISA "através de uma linguagem acessível, mas sem desvalorizar o rigor científico" (AQEDUTO, 2017), para o público em geral e para os decisores políticos. Apresenta-se como um mediador entre o conhecimento gerado pelo PISA e o público e os decisores políticos, uma vez que os seus membros se veem como habitantes do espaço entre a difícil e complexa linguagem da ciência e a simples linguagem "das massas". Os membros da equipe aQeduto veem-se a si próprios como peritos mediadores que simplificam os complexos dados das bases PISA para a compreensão de leigos. O desafio da mediação envolve a produção de análises secundárias $\mathrm{e}$ - depois - a transformação dessas análises em algo acessível a todos. Isto é, o projeto não oferece simplesmente dados para o público em geral, o objetivo é "explicar a variação dos resultados dos alunos nos testes PISA" (CONSELHO NACIONAL DE EDUCAÇÃO, 2015, p. 31). Estas explicações são apresentadas como de fato muito necessárias, de modo a que os números se tornem úteis para "municiar a opinião pública com informação credível e sustentada sobre o desempenho dos alunos portugueses, através de uma linguagem acessível, mas sem desvalorizar o rigor científico" (AQEDUTO, 2017).
São também recorrentemente descritas como baseadas em evidência, unicamente construídas a partir dos dados PISA e isentas da (sempre enganosa) interpretação. Do ponto de vista do aQeduto, para a correta compreensão da realidade do sistema educativo português, os dados devem ser mantidos intactos e a opinião deve ser deixada de lado: "Não há mãe, pai, político, comentador ou especialista que não tenha uma ligação ao sistema educativo ou uma opinião acerca dele. Mas nem sempre estão disponíveis dados e análises que nos ajudem a ir além do senso-comum ou da mera opinião" (EDUCAÇÃO EM EXAME, 2017). ${ }^{4}$

Os membros da equipe aQeduto são identificados como peritos. Acima de tudo como peritos nos métodos estatísticos do PISA, que são referidos como extremamente complexos. A coordenadora do aQeduto afirma que esta complexidade "é tão grande que uma das grandes dificuldades [da equipa foi] encontrar pessoas que ajudassem a trabalhar do ponto de vista da análise de dados" (COORDENADORA DO AQEDUTO, 2017). A expertise que os membros da equipe detêm é apresentada como consistindo num conhecimento estatístico e psicométrico muito complexo, um tipo de conhecimento escasso que não está disponível em Portugal.

Contudo, possuir esse tipo de conhecimento parece não ser suficiente para os objetivos do aQeduto, uma vez que é identificada uma insuficiência elementar no perito estatístico e uma consequente necessidade de

[...] uma equipa multidisciplinar, composta por investigadores provenientes de diferentes áreas científicas, congregando especialistas em política educativa, avaliação, comparabilidade, racionalidade económica, comunicação e estatística/análise de dados. (AQEDUTO, 2017).

A coordenadora do aQeduto foi National Project Manager do PISA (2012-2013) e detém conhecimento em análise multivariada de dados no campo da Psicologia. A equipe inclui quatro outros membros: ${ }^{5}$ David Justino, ex-Presidente do $\mathrm{CNE}$, investigador e professor de Sociologia numa

4 Ver também Ferreira (2015, p. 19), Flores, Casas-Novas e Ferreira (2015, p. 226) e aQeduto (2017).

5 Numa fase inicial, a equipe incluía outro membro que também trabalhou previamente (2008-2011) como National Project Manager do PISA. 
universidade pública e ex-Ministro da Educação (2001-2003); uma coordenadora para a análise de dados que estudou Economia; outro investigador e professor de Sociologia numa universidade pública; e um membro da equipe de assessoria técnica e científica do CNE. ${ }^{6}$

Existe uma complementaridade que se expressa em dois distintos níveis. Por um lado, os membros da equipe detêm expertise simultaneamente quanto aos métodos (estatísticos) e ao objeto (educação). Por outro, este conhecimento é tanto acadêmico (professores universitários), como prático/experiencial (membros com ligação aos contextos escolares ou experiência em comunicação).

\section{Edulog: a mediação através da expertise externa}

A vocação e o labor de mediação estão presentes no EDULOG quando é afirmado o seu objetivo de atuar como uma "ponte" entre a academia, os decisores políticos e os práticos, apoiando e fornecendo "informação e investigação objetiva" sobre o sistema educativo português para que os decisores políticos e outros atores possam tomar melhores decisões (EDULOG, 2017). O EDULOG caracteriza-se por ter uma estrutura simples e, por esse motivo, o conhecimento pericial é constituído externamente, isto é, fora da sua estrutura e/ou das suas atividades quotidianas. Este conhecimento pericial é construído quer pelo seu conselho consultivo quer através da abertura de concursos para financiamento a projetos de investigação.

O conselho consultivo do EDULOG é presidido por um antigo reitor da universidade do Porto (1985-1998) e investigador na área das políticas do ensino superior e é composto por "personalidades com elevada experiência e conhecimento de políticas, sistemas e práticas educacionais" (EDULOG, 2017), incluindo: dois ex-ministros da educação que também se tornaram consultores do presidente da república em questões educacionais - e dois ex-secretários de estado da educação; o ex-presidente da CNE, David Justino, que também participa no

6 A equipe adota abordagens quantitativas oriundas da Psicologia, da Sociologia e da Economia, o que ilustra a importância dos dados, assim como das ciências dos dados, na produção de conhecimento sobre educação em Portugal, tal como acontece noutros contextos (OZGA, 2012).
aQeduto; ex-reitores, professores e investigadores de instituições de ensino superior. O conselho incluía ainda o fundador do EDULOG, Belmiro de Azevedo, lugar que é agora ocupado por um dos seus filhos, atual administrador da Fundação Belmiro de Azevedo. Uma vez que, na sua maioria, os membros do conselho têm ou tiveram altas responsabilidades em educação, na administração educacional, no Estado ou no ensino superior, são reconhecidos por um público mais amplo como especialistas em educação e bons "fazedores de pontes" entre diferentes mundos sociais: a política, as empresas e a academia.

Para além disso, o conhecimento especializado do EDULOG é também produzido externamente através de outsourcing. Para esse efeito são abertas candidaturas regulares para o financiamento de projetos de investigação, com temas, objetivos e resultados definidos a priori e que tenham, necessariamente, uma componente prática e de intervenção. Até dezembro de 2017, o EDULOG abriu seis candidaturas para financiamento: uma sobre o impacto dos professores na aprendizagem dos alunos; uma para a criação do Observatório da Educação; uma sobre competências de gestão escolar; duas sobre a transição do ensino secundário profissional para o mercado de trabalho; e uma sobre fatores explicativos do insucesso escolar.

É interessante notar que a investigação educacional tem uma longa história de conhecimento produzido em cada um desses temas. Assim, ao invés de procurar novos conhecimentos, estas chamadas servem para "identificar os assuntos que necessitam ser esclarecidos e contribuir para isso por meio da investigação científica e respetiva divulgação acessível e inteligível" (SECRETÁRIA-GERAL DO EDULOG, 2016). Neste sentido, o EDULOG seleciona os problemas que devem estar na agenda da investigação educacional, e fixa igualmente padrões de comunicação (externa) para a investigação, atuando como mediador e como criador de conhecimento.

\section{Razões para agir}

Uma segunda característica comum a esses dois atores consiste no seu compromisso em iluminar as suas audiências e escolhas públicas. Fazem-no de acordo com as suas estruturas e os seus 
modos particulares de realizar a mediação: para o aQeduto, este processo consiste em transformar o conhecimento PISA em informação fácil e transparente para o público; para o EDULOG, trata-se de transformar conhecimento que é visto como inacessível (especialmente aquele que é produzido em contexto acadêmico) em conhecimento acessível e compreensível para todos. Em ambos os casos, esta missão de esclarecimento das suas audiências transporta uma certa visão sobre o que imaginam para os sistemas educativos e sobre as melhores formas de governá-los.

\section{Iluminar as escolhas políticas}

Nas palavras do coordenador da FFMS, o aQeduto propõe "colocar informação cá fora e fazer com que qualquer proposta e ideia esteja pelo menos baseada em informação, no melhor que existe" (NUNES, 2015). O desafio de produzir informação inclui a transformação das análises secundárias produzidas, "usando uma abordagem em linguagem muito simples, que permitisse a qualquer pessoa perceber" (COORDENADORA DO AQEDUTO, 2017.). ${ }^{7}$ Esta transformação envolve não só uma linguagem simples mas também um "grafismo acessív[el]" e um "foc[o] em temas específicos" (FERREIRA; FLORES; CASAS-NOVAS, 2017, p. 12). Para além disso, envolve um esforço considerável de disseminação daquilo que é produzido no contexto do projeto, que se expressa na adoção de "uma tónica muito dinâmica, de estar sempre em permanência a fazer sair coisas" (COORDENADORA DO AQEDUTO, 2017e na procura de um modo "intuitivo", "digital e interativo" em que "se combina o rigor dos factos com a simplicidade de os comunicar" (EDUCAÇÃO EM EXAME, 2017).

Essa mediação é também desenvolvida de forma a construir uma leitura compreensível do que existe e por meio da procura de tornar a pesquisa mais acessível, nomeadamente pela sua "disseminação [...] inteligível” (SECRETÁRIA-GERAL DO EDULOG, 2016). A secretária geral do EDULOG expressa a sua preocupação com a forma como o conhecimento gerado com o financiamento do EDULOG é compreendido e transferido para contextos de aplicação prática do seguinte modo:

7 Ver também as afirmações do anterior presidente do CNE, David Justino, em Nunes (2015).
Eu sou leiga [...], uma cidadã comum. Talvez até tenha tido mais oportunidades de educação do que a maioria, mas eu não compreendo [um relatório produzido por um grupo de investigadores com quem estamos a trabalhar]. [O conteúdo] está correto, mas o nosso papel é ter esse cuidado: preparar as informações de modo a que sejam acessíveis e inteligíveis. Nós sabemos o mundo em que vivemos. As pessoas leem de raspão, por sound bites [...]. Sabemos isso, então vamos trabalhar isso. (SECRETÁRIA-GERAL DO EDULOG, 2016).

No mesmo sentido, as preocupações com a elucidação e iluminação do público foram descritas do seguinte modo por uma das investigadoras que coordena uma das equipas que participa num dos projetos financiados pelo EDULOG: "Esperamos poder ajudar as escolas e a sociedade a conhecer cada vez melhor o que se está a passar na educação, a fazer comparações, a tomar decisões para prevenir problemas e a configurar novas intervenções" (EDULOG, 2017).

Para o EDULOG, essa procura de iluminar o público inclui a criação de um Observatório da Educação que fornece indicadores online de livre acesso sobre o sistema educativo, no que diz respeito à qualidade e ao desempenho das escolas. Com este fim, o EDULOG contratou um consórcio universitário para "definir e sistematizar um conjunto de indicadores/métricas explanatórias que permita o conhecimento da situação atual, tendências de evolução e principais dinâmicas estruturais do sistema de ensino português" (EDULOG, 2017), de modo a "alimentar as discussões políticas com factos" e contribuir para a tomada de decisão informada (SECRETÁRIA-GERAL DO EDULOG, 2016).

Reconhecendo a vocação particular do aQeduto para "municiar a opinião pública com informação credível e sustentada sobre o desempenho dos alunos portugueses" (AQEDUTO, 2017) em testes transnacionais, o EDULOG assinala que o Observatório está orientado para desenvolver indicadores nacionais e contextuais específicos, no que diz respeito aos públicos-alvo do observatório (professores, gestores escolares, famílias, municípios, empresas e empregadores) (EDULOG, 2017). Este Observatório é um bom indicador da visão do EDULOG de criar "ciclos contínuos de reflexão, recomendação, medição e análise que permitam 
avaliar o estado e evolução do sistema educativo" (EDULOG, 2017).

\section{Pressupostos sobre o sistema educativo}

A par da visão sobre os modos de governo do sistema educativo, nos textos oficiais do aQeduto e do EDULOG é possível identificar a presença de pressupostos implícitos e explícitos sobre o funcionamento do sistema educativo português.

Apesar da recorrente autorreferenciação como meros mediadores entre os dados e os leigos, os materiais do aQeduto, assim como as palavras dos membros da sua equipe, demonstram que o sistema educativo é visto como tendo necessidade de melhoria (FERREIRA; FLORES; CASAS-NOVAS, 2017; JUSTINO, 2015) e como sendo melhor conduzido por políticas baseadas em evidência (FERREIRA; FLORES; CASAS-NOVAS, 2017; FLORES; CASAS-NOVAS; FERREIRA, 2015), de modo a produzir "adultos mais produtivos e competitivos na esfera global" (FERREIRA; FLORES; CASAS-NOVAS, 2017, p. 19). Existem também considerações sobre as agendas política e investigativa, de que são exemplos a discussão persistente em torno da repetição de ano (AQEDUTO, 2017; COORDENADORA DO AQEDUTO, 2017; EDUCAÇÃO EM EXAME, 2017; FERREIRA; FLORES; CASAS-NOVAS, 2017), ou a referência à importância de se desenvolver investigação qualitativa sobre as boas práticas identificadas com recurso a métodos quantitativos (COORDENADORA DO AQEDUTO, 2017).

O EDULOG revela igualmente determinadas visões sobre a educação e os sistemas educativos. Primeiro, as regras expressas nas chamadas para financiamento de projetos de investigação demonstram uma visão funcionalista da produção de conhecimento, uma vez que pretendem "encontrar soluções" fornecendo informação para as "políticas públicas para a inovação e a mudança na Educação", "com vista à adequação entre o que se ensina e aquilo de que o país precisa" (EDULOG, 2017). Esta visão funcionalista surge a par do pressuposto de que a educação pode trazer mobilidade social, uma ideologia em torno da escola que pode resultar da proximidade do EDULOG com o mundo empresarial e o seu fundador. De acordo com o website do EDULOG, a história deste self-made man mostra o "impacto que uma educação de qualidade pode ter na vida de uma pessoa". Nas suas próprias palavras:

É conhecido que uma das figuras que mais marcaram a minha vida foi o meu professor [do ensino básico]. Um professor que exigia muito trabalho, muito rigor e muita disciplina, mas ao mesmo tempo era capaz de transmitir a paixão pela descoberta do conhecimento. Viciou-me na Educação! E deste vício que me manteve sempre a sede de aprender, que determinou o meu percurso e me fez estar sempre ligado, de diferentes formas, ao ensino, nasceu também este projeto. Acredito que é a Escola, com capacidade de estimular continuamente a aprendizagem, que terá também a capacidade de mudar uma sociedade para melhor. (EDULOG, 2017).

\section{A dimensão social: atividades e modos de intervenção na ação pública}

Quer o aQeduto quer o EDULOG desenvolvem atividades muito próximas daquelas que caracterizam o papel das "terceiras comunidades" (LINDQUIST, 1990), isto é, atividades de geração de informação, publicação e convocação das quais daremos conta nos pontos seguintes.

\section{Geração de informação}

$\mathrm{O}$ aQeduto tem o propósito de alcançar diversas audiências que podem ser sensíveis a abordagens diferentes e aderir a diferentes tipos de atividades. Esta preocupação é perceptível na variedade dos seus produtos e das suas atividades e dá forma ao modo como o "conhecimento para as massas" é produzido. A informação gerada consiste integralmente em análises secundárias dos dados da OCDE oferecidos nas bases de dados PISA e está organizada em torno de dez temas estabelecidos desde o início, nos quais uma forte proximidade ao PISA in Foucus é clara. ${ }^{8}$ Este admitido mimetismo

8 "O PISA in Focus consiste numa série de notas orientadas para a política, mensais e concisas, concebidas para descrever um tópico PISA" (ORGANISATION FOR ECONOMIC CO-OPERATION AND DEVELOPMENT, 2018). Os exemplos seguintes ilustram o mimetismo a que nos referimos: PISA in Focus 13 - "O dinheiro compra um desempenho forte no PISA?"'(ORGANISATION FOR ECONOMIC CO-OPERATION AND DEVELOPMENT, 2018) vs aQeduto Q1 - "Educação e Economia: quem vai à frente?" (AQEDUTO, 2017); PISA in Focus 7 - "Escolas privadas: quem beneficia?" (ORGANISATION FOR ECONOMIC CO-OPERATION AND DEVELOPMENT, 2018) vs aQeduto Q7 - "Público ou privado: há um modelo perfeito?” (AQEDUTO, 2017). 
(COORDENADORA DO AQEDUTO, 2017) está presente não só na definição dos dez temas concretos, como também nas escolhas que moldam as análises produzidas de modo a que sejam de fácil compreensão: os temas são transformados em questões cativantes, usando linguagem simples (ou até mesmo jargão); o tema sob análise é sujeito a comparações entre países, ao cruzamento com outras variáveis e observado ao longo de uma linha de tempo; gráficos simples e de tipo diverso são incluídos ao lado de breves explicações; e frases curtas, atraentes e incisivas guiam a narrativa.

Seguindo uma abordagem diferente, o EDULOG procura identificar "buracos [...] no conhecimento que temos sobre a educação em Portugal" (SECRETÁRIA-GERAL DO EDULOG, 2016) sobre os quais é necessária mais investigação, abrindo chamadas regulares para o financiamento de projetos de investigação, como mencionado anteriormente. O ethos por trás das atividades de geração de informação é exemplarmente sintetizado com a seguinte afirmação da secretária geral do EDULOG: "Somos objetivos mas não somos neutros" (SECRETÁRIA-GERAL DO EDULOG, 2016). Por um lado, esta afirmação ilustra a procura de uma certa objetividade que advém dos números e o foco na geração e disseminação de dados para iluminar as escolhas públicas e privadas. Por outro lado, a afirmação indica que o EDULOG não pretende ser um ator neutro. Pelo contrário, confirma o seu desejo de participar na construção da agenda educacional, nomeadamente a agenda da investigação educacional.

\section{Publicação}

O mimetismo do aQeduto em relação ao PISA in Focus está igualmente presente na publicação mensal de onze folhetos (um para cada tema, mais um final), distribuídos em formato de papel e publicados no website do projeto e na sua página no Facebook, assim como numa revista nacional online. Além disso, tanto o website do aQeduto como o relatório final são totalmente organizados em torno desses temas, o que demonstra quão fortemente estrutural é a definição dos dez temas concretos, não apenas para as atividades de geração de informação, mas também para as atividades de publicação. Este ritmo mensal é também visível na significativa presença do aQeduto na mídia ao longo de 2016, que é resultado, juntamente com os materiais acima descritos, de um grande investimento em disseminação. Este esforço é descrito de forma explícita e esclarecedora no relatório final do aQeduto:

Apostou-se assim numa linguagem e grafismo acessíveis para comunicar os resultados do projeto; numa abordagem focada em temas específicos e delimitados apresentados em fóruns de debate mensais [...]; na criação e distribuição mensal de 11 brochuras com a síntese dos estudos numa tiragem total de 2500 exemplares; na mobilização de canais de comunicação institucionais, nomeadamente o site e redes sociais do aQeduto e parceiros (CNE e FFMS); num investimento no trabalho com os órgãos de comunicação social que fizeram a cobertura e divulgação de todos os tópicos apresentados, quer na imprensa escrita, quer na imprensa online. Este investimento resultou na publicação de cerca de 250 artigos em jornais e revistas, entrevistas em rádios, presença em programas de informação televisivos e blogs de opinião. (FERREIRA; FLORES; CASAS-NOVAS, 2017, p. 12).

O EDULOG é fortemente orientado para as plataformas digitais. $\mathrm{O}$ seu website foi concebido como uma plataforma interativa, responsiva e amigável, com o objetivo de alcançar uma grande variedade de utilizadores. É aí publicada uma extensa gama de informação, incluindo notícias sobre eventos e recortes da mídia sobre educação; vídeos e relatórios de investigação que podem ser visualizados e/ou descarregados gratuitamente. Além disso, o EDULOG está presente no Facebook, Twitter, Google+ e YouTube. Mesmo em meio período, um jornalista trabalha para o EDULOG, recolhendo notícias sobre educação e preparando materiais online, o que demonstra a importância atribuída a estes meios para disseminar uma mensagem e obter maior visibilidade e reputação junto à opinião pública.

\section{Convocação}

$\mathrm{O}$ aQeduto organizou onze seminários mensais com duração de meio dia, cobertos na mídia e com significativo apoio logístico da FFMS. Estes seminários foram concebidos como oportunidades para a disseminação de cada folheto e para "tentar dialo- 
gar mais com as pessoas" (COORDENADORADO AQEDUTO, 2017). Os dez primeiros seminários foram dedicados à apresentação das informações geradas sobre os dez temas mensais, seguida de um período aberto a questões do público. O décimo primeiro seminário pretendia encerrar os trabalhos, revisitando assim todos os dez temas e fazendo parte do "Mês da educação", um evento anual da FFMS que inclui várias palestras e seminários. Curiosamente, este último seminário foi organizado de uma forma inovadora, que incluiu uma avaliação da recepção pelo público das informações geradas ao longo dos dez meses, naquilo que pode ser visto como uma tentativa de compreender se as "lições foram aprendidas". 9

O EDULOG promove eventos informais periódicos abertos ao público - os EDUTALKS - e conferências para disseminar os resultados preliminares dos projetos de investigação que financia. Além disso, promove conferências anuais com um foco mais científico. Até 2017, foram realizadas três conferências: uma primeira para discutir as perceções dos portugueses sobre o valor da educação; uma segunda dedicada ao desenvolvimento econômico na Europa do sul; e, finalmente, uma terceira que consistiu num encontro internacional dedicado ao tema "Educação científica e desenvolvimento económico". Os temas destas atividades de convocação deixam antever que estes encontros mobilizam para um debate em torno da educação e sua relação com o desenvolvimento social e econômico do país.

\section{Formas mais interativas e intuitivas de disse- minação do conhecimento}

Para além dessas atividades de geração de informação, publicação e convocação, identificamos o que parece constituir uma nova (e mais sofisticada) atividade, na procura de formas de disseminação do conhecimento mais interativas e intuitivas. Esta

9 Nos dias anteriores ao último seminário, foi pedido aos participantes inscritos que respondessem (numa plataforma online) a dez questões de escolha múltipla relacionadas com as análises secundárias produzidas no âmbito do aQeduto (e.g. Frequentar o pré escolar afeta os resultados dos alunos aos 15 anos?; Qual a percentagem de mães portuguesas que estudaram apenas até ao $9^{\circ}$ ano ou menos?). Foram depois projetados ao longo da apresentação gráficos com as respostas dos participantes, com o mote 'Aprenderam bem a lição?', em conjunto com um sumário da informação gerada para cada tema. ação concretiza-se através do recurso a plataformas digitais por meio das quais são disponibilizados dados passíveis de consulta, customização e visualização. A presença destes novos modos de ação parecem ser inseparáveis do surgimento de novas formas de orientar, coordenar e controlar os sistemas de ensino, em que o monitoramento cíclico de dados e informações se torna central na regulação da educação (SIMONS, 2014; WILLIAMSON, 2016a; 2016b).

Em associação com um jornal nacional semanal, os materiais produzidos no âmbito do aQeduto foram recentemente transformados numa plataforma digital alojada no website da FFMS. Com o nome Educação em Exame, esta plataforma reúne as análises secundárias sobre os dez temas e está organizada de uma forma inovadora, de modo a permitir que os visitantes possam também obter ou interagir com outros recursos: informação sobre os testes PISA; um mapa comparativo no qual os utilizadores podem escolher que dados ver representados; uma amostra de questões do teste PISA às quais é possível responder; informação adicional sobre o sistema educativo português; a possibilidade de ver a evolução do investimento em educação em Portugal comparado com outros países; entre muitos outros. Este dispositivo apresenta novas características em contexto nacional, não só por recorrer a dados de um teste realizado por uma organização internacional e os apresentar em comparação com os resultados de outros países, mas também pelo considerável grau de interatividade projetada, uma vez que os utilizadores são convidados a manipular os dados que desejam obter, a concluir um teste ou a assistir a vídeos.

Indo na mesma direção, o Observatório da Educação do EDULOG, que ainda está em fase de concretização, foi projetado como uma plataforma online interativa que os utilizadores podem explorar de acordo com os seus objetivos e interesses, incluindo a possibilidade de fazer comparações entre escolas quanto aos seus desempenhos (EDULOG, 2017).

\section{Linhas conclusivas}

Este estudo focou-se na emergência de duas organizações de pequena escala, ligadas a organi- 
zações filantrópicas, que operam no espaço público educativo desenvolvendo atividades que visam orientar e dar sentido a outros atores sobre o seu envolvimento nos processos políticos. Três linhas conclusivas resultam da nossa análise interpretativa sobre o seu papel como atores intermediários.

\section{Complexidade dos processos políticos}

Em primeiro lugar, o surgimento e crescente afirmação desses novos mediadores e especialistas permite colocar a hipótese de um aumento da complexidade dos processos políticos em Portugal. Esta poderá resultar da expansão de atores sociais que se (auto)posicionam como atores reflexivos e atores indutores da reflexão e que trazem para o espaço público seus questionamentos sobre a realidade do sistema educativo e prescrições sobre o modo como - e em que sentido - deve ser orientado. E resultará, ainda, do aumento da quantidade de informação e, eventualmente, de conhecimento que esses atores fazem circular nos espaços em que a política é promulgada e legitimada e, possivelmente, nos espaços de construção das políticas.

\section{Regras para as políticas e regras para o conhecimento}

Em segundo lugar, esses atores ativam quadros cognitivos, implícitos e explícitos, para ler e interpretar o cenário educativo português, particularmente visíveis na diversidade de atividades (de publicação, convocação etc.) que põem em marcha. Essas regras estabelecem conexões normativas entre o governo e a informação e entre o conhecimento educacional e a direção dos sistemas educativos. Os processos de governo da educação baseados em indicadores de performance para outros atores (estudantes, professores, gestores e políticos) e/ou para as escolas e sistema educativo são legitimados quer através da sua problematização, quer pelas prescrições que visam a mudança da realidade educacional. Do mesmo modo, são legitimadas formas particulares de conhecimento educacional - as consideradas capazes de encontrar soluções e de gerar inovações requeridas para um sistema educacional que é permanentemente apresentado como necessitado de melhoria e/ou desajustado em face das exigências de suas dimensões econômicas, sociais e culturais. Em última análise, as escolhas sobre a pesquisa a ser disseminada ou a ser financiada produzem a legitimação de um certo tipo de conhecimento e certos produtores de conhecimento e apoiam sua existência e expansão. Apoiar a produção de conhecimento para políticas é também fazer uma política de conhecimento (VISEU; CARVALHO, 2018).

\section{Um novo acordo tácito}

Por último, esses atores atualizam e expandem as relações entre as elites na fabricação da política. Ainda que não possamos afirmar que assistimos a uma mudança do "governo para a governança" (OZGA, 2009), o estudo mostra a emergência de novos espaços intermediários de política nos quais participam atores estatais e/ou atores que o representaram prolongadamente e especialistas com um importante capital social, acadêmico e político. É preciso notar que muitos destes atores não são novos nos processos da política educativa nacional. Pelo contrário, são atores que têm tido uma presença na cena educativa, mas que agora intervêm de outro modo para legitimar um conjunto de valores e crenças sobre o sistema educativo, visando novos modos de governo. De certo modo, esses atores configuram e/ou estabelecem relações muito próximas com as elites político-administrativas que têm excluído "práticos", professores, entendidos como receptores e/ou objetos de pesquisa. Este fenômeno sinaliza, enfim, a desvalorização da regulação burocrático-profissional, e o desenvolvimento de processos de uma regulação baseada no conhecimento, na qual os saberes periciais substituem os saberes estatais e os saberes profissionais, legitimados por aquilo que parece configurar um novo acordo tácito entre filantropia e academia.

\section{REFERÊNCIAS}

AQEDUTO. Apresentação. 2017. Disponível em: <http://www.aqeduto.pt/apresentacao/>. Acesso em: 5 set. 2017. BALL, Stephen. Following policy: networks, network ethnography and education policy mobilities. Journal of 
Education Policy, v. 31, n. 5, p. 549-566, 2016.

BARROSO, João. A emergência do local e os novos modos de regulação das políticas educativas. Educação: Temas e Problemas, v. 12 e 13, p. 13-25, 2013.

BERNARDI, Liane Maria. Et al. Os think tanks liberais no País: a Universidade Aberta de Porto Alegre. Retratos da Escola, v. 11, n. 21, p. 571-586, 2018.

CARVALHO, Luís Miguel. Apontamentos sobre as relações entre conhecimento e política educativa. Revista do Fórum Português de Administração Educacional, n. 6, p. 37-45, 2006.

CARVALHO, Luís Miguel; COSTA, Estela; GONÇALVES, Catarina. Fifteen years looking at the mirror: on the presence of PISA in education policy processes (Portugal, 2000-2016). European Journal of Education, v. 52, n. 2, p. 154-65, 2017.

COHEN, Louis; MANION, Lawrence; MORRISON, Keith. Research methods in education. London: Routledge-Falmer, 2007.

CONSELHO NACIONAL DE EDUCAÇÃO - CNE. Resultados do PISA e os ambientes escolares. In: Estado da Educação 2015. Lisboa, 2015. p. 31-39.

CORREIA, Luísa. Alberto Amaral: "Impressiona-me a falta de continuidade nas políticas" de educação. JPN JornalismoPortoNet, Porto, 16 maio 2017. Disponível em: <https://jpn.up.pt/2017/05/16/alberto-amaral-impressiona-me-falta-continuidade-nas-politicas-educacao/>. Acesso em: 19 dez. 2017.

EDUCAÇÃO EM EXAME. Sobre o projeto. 2017. Disponível em: <https://educacaoemexame.pt/>. Acesso em: 20 set. 2017.

EDULOG. Think tank da educação. 2017. Disponível em: <https://www.edulog.pt/>. Acesso em: 19 dez. 2017.

FELDFEBER, Myriam. Policies for teacher training and work in Argentina from the turn of the century. In: NORMAND, Romuald. Et al (Ed.). Education policies and the restructuring of the educational profession. Singapore: Springer, 2018. p. 89-103.

FERREIRA, Ana. Projeto aQeduto - avaliação, qualidade e equidade do sistema educativo em Portugal. In: CONSELHO NACIONAL DE EDUCAÇÃO. Investigação em educação e os resultados do PISA. Lisboa, 2015. p. 19-29.

FERREIRA, Ana; FLORES, Isabel; CASAS-NOVAS, Teresa. Porque melhoraram os resultados PISA em Portugal: estudo longitudinal e comparado (2000-2015). Lisboa: Fundação Francisco Manuel dos Santos, 2017.

FLORES, Isabel; CASAS-NOVAS, Teresa; FERREIRA, Ana. Projeto aQeduto: o que mudou na educação em Portugal - doze anos de avaliação internacional. In: CONSELHO NACIONAL DE EDUCAÇÃO. O estado da educação 2015. Lisboa, 2015. p. 226-251.

FUNDAÇÃO FRANCISCO MANUEL DOS SANTOS - FFMS. Sobre a Fundação. 2017. Disponível em: <https:// www.ffms.pt/sobre-a-fundacao $>$. Acesso em: 5 set. 2017.

HOWARD, Philip. Network ethnography and the hypermedia organization: New media, new organizations, new methods. New media \& society, v. 4, n. 4, p. 550-574. 2002.

JUSTINO, David. Encerramento. In: CONSELHO NACIONAL DE EDUCAÇÃO. Investigação em educação e os resultados do PISA. Lisboa, 2015. p. 118-123.

LAWN, Martin; LINGARD, Bob. Constructing a European policy space in educational governance: the role of transnational policy actors. European Educational Research Journal, v. 1, n. 2, p. 290-307, 2002.

LEVIN, Ben; COOPER, Amanda. Theory, research and practice in mobilizing research knowledge in education. In: FENWICK, Tara; FARRELL, Lesley (Ed.). Knowledge Mobilization and Educational Research. London: Routledge, 2012. p. 17-29.

LINDQUIST, Evert. The third community, policy inquiry, and social scientists. In: BROOKS, Stephen; GAGNON, Alain-G. (Ed.). Social scientists, policy, and the state. New York: Praeger, 1990. p. 21-51.

MAROY, Christian. Towards post-bureaucratic modes of governance: a European perspective. In: WALDOW, Florian; STEINER-KHAMSI, Gita (Ed.). Policy borrowing and lending in education. London: Routledge, 2012. p. 62-79.

MARTINS, Erika. Todos pela educação? Como os empresários estão determinando a política educacional brasi- 
leira. Rio de Janeiro: Lamparina, 2016.

MCGANN, James G. 2017 global go to think tank index report. TTCSP Global Go To Think Tank Index Reports, n. 13, 2018. Disponível em: $<$ https://repository.upenn.edu/cgi/viewcontent.cgi?article=1012\&context=think_tanks $>$. Acesso em: 15 out. 2018.

NAY, Olivier; SMITH, Andy. Les intermédiaries en politique: mediation et jeux d'instituitions. In : .(Ed.). Le gouvernement du compromise: courtiers et généralistes dans l'action politique. Paris: Economica, 2002. p. 1-21.

NUNES, Flávio. Projeto aQeduto: os alunos têm melhores resultados. Mas porquê? Observador, Lisboa, 15 dez. 2015. Disponível em: $<$ https://observador.pt/2015/12/15/projeto-aqeduto-os-alunos-melhores-resultados/>. Acesso em: 20 jul. 2017.

ORGANISATION FOR ECONOMIC CO-OPERATION AND DEVELOPMENT - OECD. PISA in Focus. 2018. Disponível em: <https://www.oecd.org/pisa/pisaproducts/pisainfocus.htm>. Acesso em: 8 set. 2017.

OZGA, Jenny. Governing knowledge: Research steering and research quality. European Educational Research Journal, v. 7, n. 3, p. 261-272, 2008.

. Governing education through data in England: From regulation to self-evaluation. Journal of Education Policy, v. 24, n. 2, p. 149-162, 2009.

. Assessing PISA. European Educational Research Journal, v. 11, n. 2, p. 166-171. 2012.

SIMONS, Maarten. Governing through feedback: from national orientation towards global positioning. In: FENWICK, Tara; MANGEZ, Eric; OZGA, Jenny (Ed.). World Yearbook of Education 2014: governing knowledge: comparison, knowledge-based technologies and expertise in the regulation of education. London: Routledge, 2014. p. $155-171$.

VAN ZANTEN, Agnes. Connaissances et politiques d'éducation: Quelles interactions? Revue Française de Pédagogie, v. 1, n. 182, p. 5-8, 2013.

VISEU, Sofia; CARVALHO, Luís Miguel. Think tanks, policy networks and education governance: the rising of new intra-national spaces of policy in Portugal. Education Policy Analysis Archives, v. 26, n. 108, p. 1-26, sep. 2018.

WILLIAMSON, Ben. Digital education governance: data visualization, predictive analytics, and 'real-time' policy instruments. Journal of Education Policy, v. 31, n. 2, p. 123-141, $2016 \mathrm{a}$.

Digital methodologies of education governance: Pearson plc and the remediation of methods. European

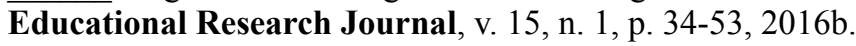

